\title{
Effect of trifluoperazine, a calmodulin antagonist, on prostaglandin output from the guinea-pig uterus
}

\author{
N. L. Poyser \\ Department of Pharmacology, University of Edinburgh Medical School, I George Square, \\ Edinburgh EH8 9JZ, U.K.
}

\begin{abstract}
Summary. Trifluoperazine, a calmodulin antagonist, inhibited the A23187-induced increase in outputs of prostaglandin (PG) F- $2 \alpha$ and 6-oxo-PGF- $1 \alpha$ from the Day 7 and Day 15 guinea-pig uterus superfused in vitro. The basal outputs of, and the arachidonic acid-induced increase in outputs of PGF-2 $\alpha$, PGE-2 and 6-oxo-PGF-1 $\alpha$ from the guinea-pig uterus were not inhibited by trifluoperazine. In contrast, indomethacin inhibited A23187-stimulated, arachidonic acid-stimulated and the basal outputs of PGs from the guinea-pig uterus, indicating that trifluoperazine was not inhibiting cyclo-oxygenase. Since the action of A23187 is dependent upon extracellular $\mathrm{Ca}^{2+}$, the present findings provide evidence that calmodulin is involved in $\mathrm{Ca}^{2+}$-induced increases in uterine PG output from the guinea-pig uterus.

Trifluoperazine, but not indomethacin, inhibited A23187-induced contraction of the guinea-pig uterus, which is consistent with calmodulin being involved in smooth muscle contraction. Arachidonic acid treatment did not contract the guinea-pig uterus. These findings indicate that PGs are not involved in the contraction induced by A23187. Other findings of interest were (i) trifluoperazine caused a small, sometimes significant $(P<0.05)$, increase in uterine PG output, (ii) exogenous arachidonic acid failed to increase PGF- $2 \alpha$ output from the Day 15 uterus in contrast to the stimulant action of A23187, and (iii) exogenous arachidonic acid caused a fairly large increase in uterine PGE-2 output in contrast to the small effect with A23187.
\end{abstract}

\section{Introduction}

Much evidence indicates that prostaglandin (PG) F-2 $\alpha$ is the uterine luteolytic hormone in the guinea-pig (see Poyser, 1976, 1981). The outputs of PGF-2 $\alpha$, PGE-2, 6-oxo-PGF-1 $\alpha$ and thromboxane (TX) B-2 from the guinea-pig uterus superfused in vitro increase 21.9-, 1·8-, 2.9- and 1·2-fold, respectively, between Days 7 and 15 of the oestrous cycle (Poyser \& Brydon, 1983). Oestradiol acting on a progesterone-primed uterus is probably responsible for this relatively specific increase in PGF-2 $\alpha$ output (Poyser, 1983a). Oxytocin does not appear to be involved (Poyser \& Brydon, 1983). The calcium ionophore, A23187, stimulates PG release from the Day-7 and Day-15 guineapig uterus superfused in vitro (Poyser \& Brydon, 1983), an action dependent upon the presence of extracellular $\mathrm{Ca}^{2+}$ (Poyser, 1984a). Increasing the free intracellular $\mathrm{Ca}^{2+}$ concentration stimulates uterine PG synthesis and release, probably by activating phospholipase A-2 (PLA-2; EC 3.1.1.4), which is the enzyme responsible for releasing arachidonic acid from phospholipids for conversion into PGs. This activation of PLA-2 by $\mathrm{Ca}^{2+}$ is considered to be of prime importance in the mechanism by which oestradiol acting on a progesterone-primed uterus 'switches on' PGF- $2 \alpha$ synthesis and release from the guinea-pig endometrium after Day 11 of the cycle (Downing \& Poyser, 1983). This raises the question as to whether $\mathrm{Ca}^{2+}$ exerts its effect on the uterus by combining with the intracellular calcium receptor, calmodulin, especially as PLA-2 in other tissues 
is a calmodulin-dependent enzyme (Wong \& Cheung, 1979; Maskowitz, Shapiro, Schook \& Puzkin, 1983). Consequently, the effect of trifluoperazine, a calmodulin antagonist (Levin \& Weiss, 1977), on PG output from the guinea-pig uterus has been examined. The actions of trifluoperazine have been contrasted with those of indomethacin, a cyclo-oxygenase inhibitor.

\section{Materials and Methods}

Fifty virgin guinea-pigs weighing $650-900 \mathrm{~g}$ were examined daily and a vaginal smear was taken when the vagina was perforate. The first day of the cycle was taken as the day preceding the postovulatory influx of leucocytes when cornification was at a maximum. All guinea-pigs used had previously shown normal cycles. They were killed, by stunning and incising the neck, on Day 7 or Day 15 of the cycle. The two uterine horns in each guinea-pig were removed, weighed, and 'opened' by cutting longitudinally. Each uterine horn was suspended in an organ bath and attached to an isotonic lever under a tension of $2 \mathrm{~g}$. Both uterine horns were superfused independently with Krebs' solution ( $5 \mathrm{ml} / \mathrm{min}$; for composition, see Mitchell, Poyser \& Wilson, 1977) at $37^{\circ} \mathrm{C}$, pre-gassed with $5 \% \mathrm{CO}_{2}, 95 \% \mathrm{O}_{2}$. After an initial settling period of $60 \mathrm{~min}$, samples of superfusate were collected for 10 -min periods consecutively over the next $100 \mathrm{~min}$ (i.e. 10 samples/uterine horn). Additions of trifluoperazine (30 or $100 \mu \mathrm{M}), \mathrm{A} 23187(1 \mu \mathrm{g} / \mathrm{ml})$, indomethacin $(5.6 \mu \mathrm{M})$ and arachidonic acid (1 $\mu \mathrm{g} / \mathrm{ml})$ were made to the Krebs' solution, before it was superfused over the tissue, during the collection of samples 4-7 and/or 6 and 7 (5 guinea-pigs/experiment).

After collection, the $\mathrm{pH}$ of each sample was lowered to 4.0 with $10 \mathrm{~N}-\mathrm{HCl}$, and the PGs present were extracted by shaking twice with $50 \mathrm{ml}$ ethyl acetate. The two ethyl acetate fractions were combined and evaporated to dryness on a rotary evaporator at $45^{\circ} \mathrm{C}$. Each extract was re-dissolved in 10 $\mathrm{ml}$ ethyl acetate and stored at $-20^{\circ} \mathrm{C}$ before the amounts of PGF- $2 \alpha$, PGE-2 and 6-oxo-PGF- $1 \alpha$ present were measured by radioimmunoassay (RIA) as described previously (Poyser, 1984b). During the periods of superfusate collection, the tone of the uterus was noted.

Sources of drugs and chemicals. Arachidonic acid and A23187 were from Sigma Chemical Co. Ltd (Poole, Dorset, U.K.); trifluoperazine (from Smith, Kline \& French Laboratories Ltd) (Welwyn Garden City, Herts, U.K.); and indomethacin (from Merck Sharpe \& Dohme Ltd) (Hoddesdon, Herts, U.K.).

Statistical tests. Changes in the output of a particular PG with time were analysed by Duncan's multiple range test. However, if the variances of some of the groups were unequal by the variance " $F$ " ratio test, changes in output were analysed by the appropriate use of Student's $t$ test or a modified $t$ test for unequal variances. Other comparisons were made using the paired $t$ test.

\section{Results}

\section{Uterine PG output}

Trifluoperazine $(100 \mu \mathrm{M})$ caused a small and, in some instances, a significant $(P<0.05)$ increase in the outputs of PGF- $2 \alpha$, PGE-2 and 6-oxo-PGF-1 $\alpha$, from the Day-7 and Day-15 guinea-pig uterus (Text-figs la \& 2a). A23187 significantly $(P<0.05)$ increased the outputs of PGF-2 $\alpha$ and 6oxo-PGF- $1 \alpha$ but had little effect on the output of PGE-2, from the Day-7 and Day-15 uterus. Trifluoperazine $(100 \mu \mathrm{M})$ inhibited this stimulatory effect of $\mathrm{A} 23187$, but it had a more marked effect on PGF- $2 \alpha$ output than on 6-oxo-PGF- $1 \alpha$ output (Text-figs $1 b \& 2 b$ ). In fact, the maximum outputs of 6-oxo-PGF-1 $\alpha$ on Day 15 were not significantly different in the absence or presence of trifluoperazine $(100 \mu \mathrm{M})$, although the time taken to reach the maximum output was significantly $(P<0.05)$ longer in the presence of trifluoperazine $(100 \mu \mathrm{M}$; Text-fig. 2b). 


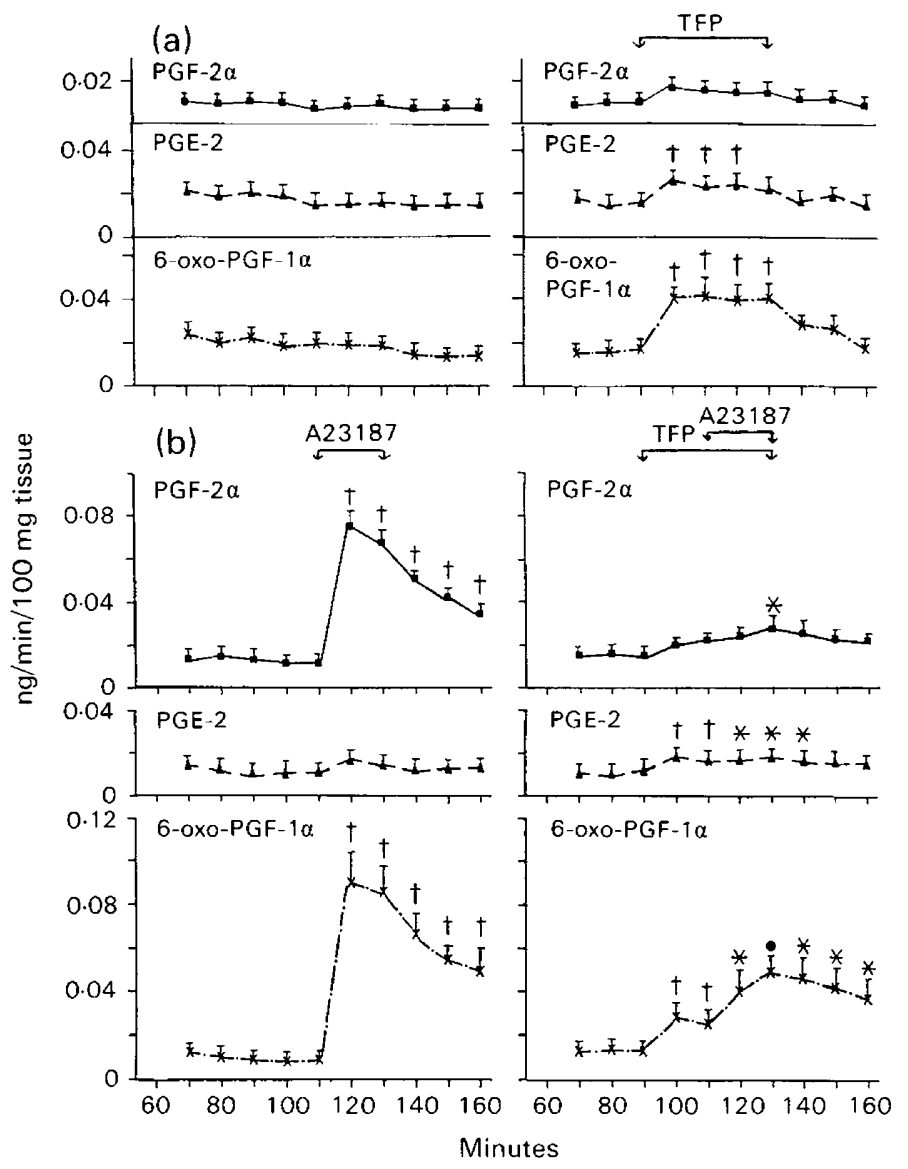

Text-fig. 1. Effect of trifluoperazine (TFP; $100 \mu \mathrm{M}$ ) on (a) basal and (b) A23187-stimulated mean ( \pm s.e.m., $n=5$ ) outputs of prostaglandin (PG) F-2 $\alpha, P G E-2$ and 6-oxo-PGF-1 $\alpha$ from the Day -7 guinea-pig uterus superfused in vitro. For any one $P G$ receiving any particular treatment on only the left-hand or right-hand side: $†$ Significantly greater than values before any treatment $(P<0.05)$; ${ }^{*}$ Significantly greater than values before any treatment but not with TFP treatment alone $(P<0.05)$; Significantly greater than values before any treatment and with TFP treatment alone, but not significantly different from the values marked with ${ }^{*}(P<0.05)$.

Trifluoperazine at $30 \mu \mathrm{M}$ had no effect on A23187-induced increases in PG outputs from the Day-7 and Day-15 guinea-pig uterus, except that the maximum output of PGF- $2 \alpha$ induced by A23187 on Day 7 was significantly $(P<0.05)$ lower in the presence of trifluoperazine $(30 \mu \mathrm{M})$ than in its absence (Text-fig. 3a). Arachidonic acid $(1 \mu \mathrm{g} / \mathrm{ml})$ significantly $(P<0.05)$ increased the outputs of PGF-2 $\alpha$, PGE-2 and 6-oxo-PGF-1 $\alpha$ from the Day-7 guinea-pig uterus and, with the exception of PGF- $2 \alpha$ output, from the Day-15 guinea-pig uterus (Text-figs 4a \& 5b). Trifluoperazine ( 100 $\mu \mathrm{M})$ had no inhibitory effect on arachidonic acid-induced increases in PG outputs from the Day-7 and Day-15 uterus (Text-figs $4 \mathrm{a}$ and $4 \mathrm{~b}$ ). These increases induced by arachidonic acid were additional to the small increases induced by trifluoperazine $(100 \mu \mathrm{M}$; Text-fig. $4 \mathrm{~b})$. In fact, the arachidonic acid-induced increase in 6-oxo-PGF-1 $\alpha$ on Day 7 was significantly $(P<0.05)$ greater in the presence of trifluoperazine $(100 \mu \mathrm{M})$ than in its absence, even after allowing for the small increase induced by trifluoperazine $(100 \mu \mathrm{M})$ alone (Text-fig. $4 \mathrm{a})$. Indomethacin $(5.6 \mu \mathrm{M})$ significantly $(P<$ $0 \cdot 05$ ) inhibited the basal outputs of PGF-2 $\alpha$, PGE-2 and 6-oxo-PGF-1 $\alpha$ from the Day-15 guinea-pig uterus (Text-fig. 5a), and prevented the increases in PG outputs normally induced by A23187 and arachidonic acid (Text-figs $5 \mathrm{a} \& 5 \mathrm{~b}$ ). 


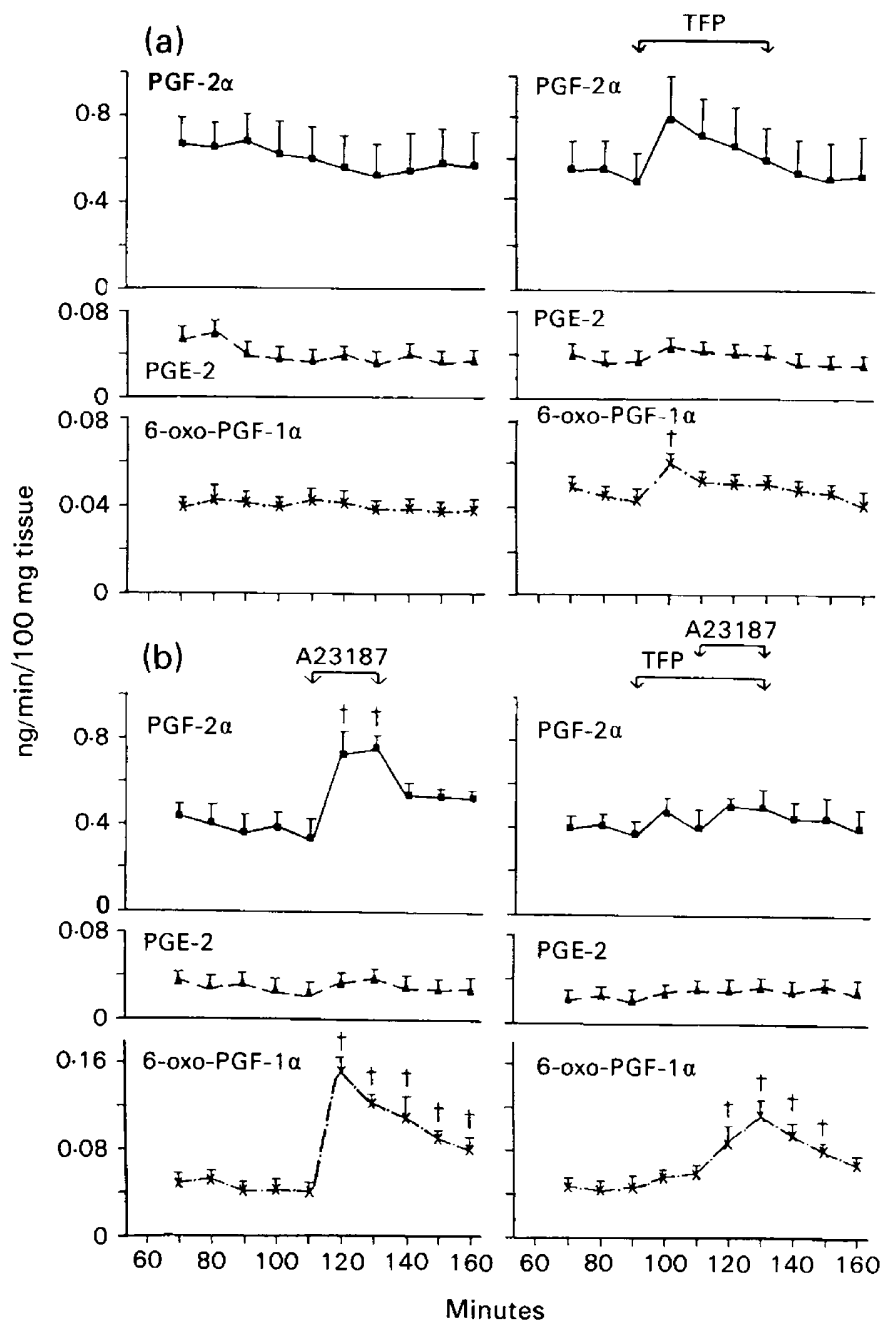

Text-fig. 2. Effect of trifluoperazine (TFP; $100 \mu \mathrm{M}$ ) on (a) basal and (b) A23187-stimulated mean ( \pm s.e.m., $n=5$ ) outputs of prostaglandin (PG) F-2 $\alpha$, PGE-2 and 6-oxo-PGF- $1 \alpha$ from the Day-15 guinea-pig uterus superfused in vitro. For any one $P G$ receiving any particular treatment on only the left-hand or right-hand side: †Significantly greater than values before treatment with A23187 $(P<0.05)$.

\section{Uterine tone}

Each uterine horn showed occasional, spontaneous contractions of short duration $(<1 \mathrm{~min})$ which occurred at random during the period of superfusion. The addition of trifluoperazine ( 30 or $100 \mu \mathrm{M})$, indomethacin $(5.6 \mu \mathrm{M})$ or arachidonic acid $(1 \mu \mathrm{g} / \mathrm{ml})$ had no effect on the incidence of these spontaneous contractions. When A23187 was used, the uterine horn slowly contracted during the first minute of A23187 treatment and then remained fully contracted during the rest of the experiment, even when the A23187 was removed, although the Day-15 uterine horns showed short periods $(<1 \mathrm{~min})$ of partial relaxation. Trifluoperazine $(100$ but not $30 \mu \mathrm{M})$ prevented the contraction induced by A23187, but the uterine horns still exhibited their random, spontaneous contractions during and after this combined treatment. Indomethacin $(5 \cdot 6 \mu \mathrm{M})$ had no effect on the A23187-induced contraction. 


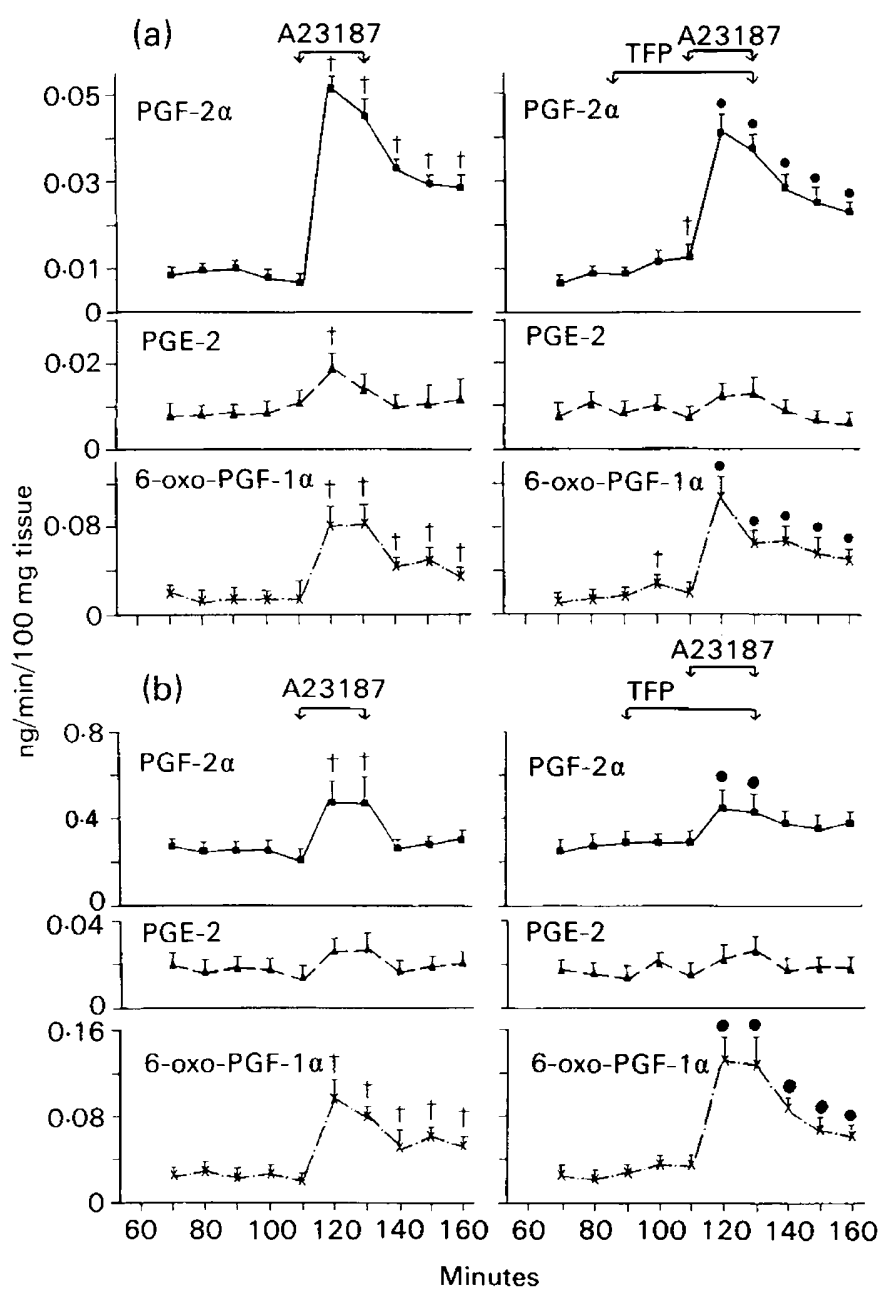

Text-fig. 3. Effect of trifluoperazine (TFP; $30 \mu \mathrm{M}$ ) on A23187-stimulated mean ( \pm s.e.m., $n=$ 5) outputs of prostaglandin (PG) F- $2 \alpha$, PGE-2 and 6-oxo-PGF- $1 \alpha$ from the (a) Day-7 and (b) Day-15 guinea-pig uterus superfused in vitro. For any one $P G$ receiving any particular treatment on only the left-hand or right-hand side: $†$ Significantly greater than values before any treatment $(P<0.05)$; Significantly greater than values before any treatment and with TFP treatment alone $(P<0.05)$.

\section{Discussion}

Trifluoperazine at $100 \mu \mathrm{M}$ inhibited or delayed the A23187-induced increases in PGF-2 $\alpha$ and 6-oxoPGF-1 $\alpha$ outputs from the Day-7 and Day-15 guinea-pig uterus superfused in vitro. Trifluoperazine at $30 \mu \mathrm{M}$ had no such effect except for producing a small reduction in the maximum output of PGF$2 \alpha$ induced by $A 23187$ on Day 7 . At $100 \mu \mathrm{M}$, trifluoperazine had no inhibitory effect on arachidonic acid-induced increases in PG output from the guinea-pig uterus, and did not reduce the basal output of PGs. Indomethacin (5.6 $\mu \mathrm{M})$ inhibited basal PG output, and the A23187-induced and arachidonic acid-induced increases in PG output from the uterus. Trifluoperazine had a different profile of effects when compared to indomethacin, indicating that trifluoperazine was not acting as a cyclooxygenase inhibitor in the uterus. Since (i) the action of A23187 is dependent upon extracellular 


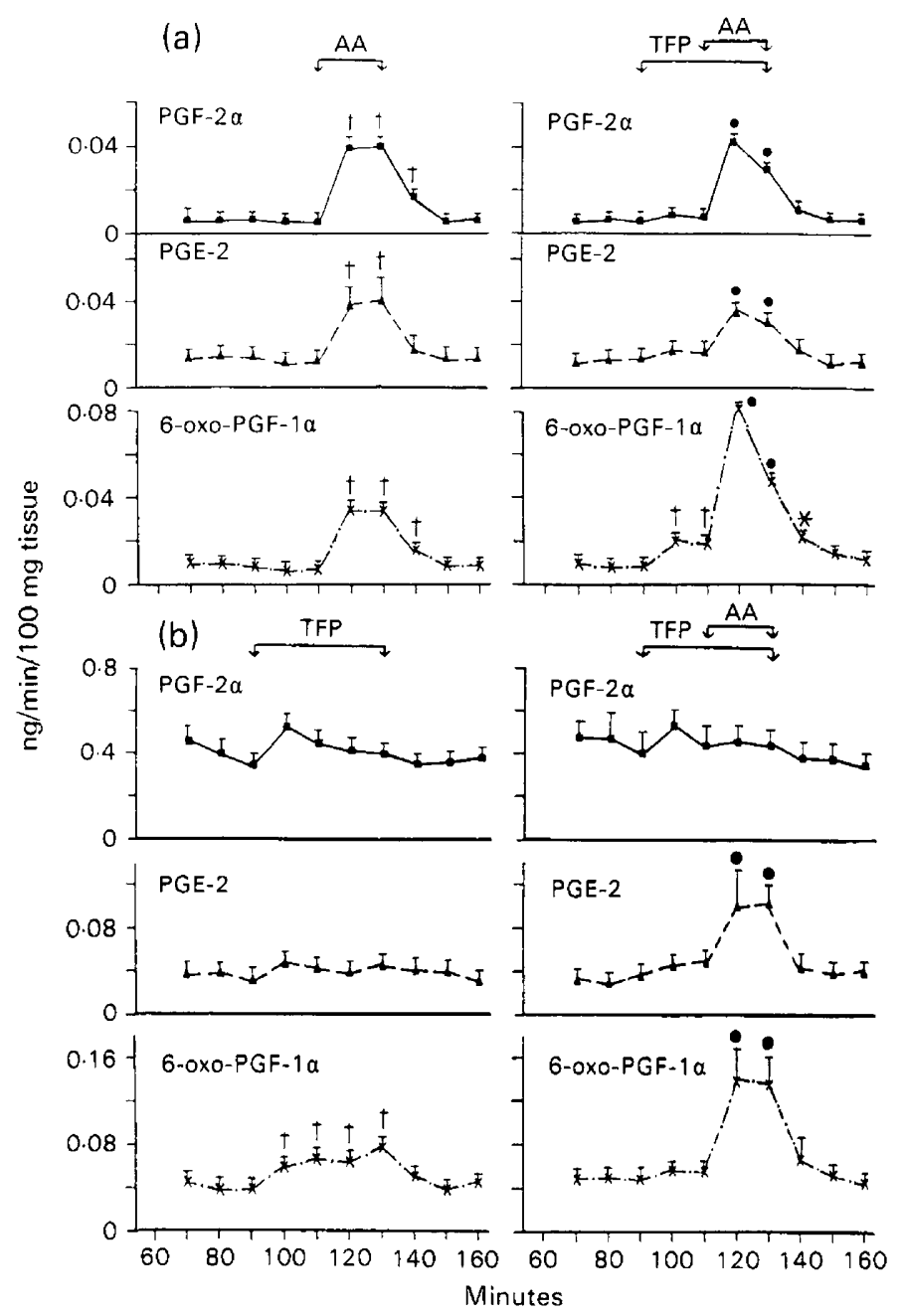

Text-fig. 4. Effect of trifluoperazine (TFP; $100 \mu \mathrm{M}$ ) on arachidonic acid-stimulated mean ( \pm s.e.m., $n=5$ ) outputs of prostaglandin (PG) F-2 $\alpha$, PGE-2 and 6-oxo-PGF- $1 \alpha$ from the (a) Day-7 and (b) Day-15 guinea-pig uterus superfused in vitro. For any one PG receiving any particular treatment on only the left-hand or right-hand side: †Significantly greater than values before any treatment $(P<0.05)$; Significantly greater than values before any treatment and with TFP treatment alone $(P<0.05)$.

$\mathrm{Ca}^{2+}$ (Poyser, 1984a), and (ii) trifluoperazine is a calmodulin antagonist (Levin \& Weiss, 1977), the inhibition of A23187-induced increases in uterine PG output is consistent with calmodulin being involved in the process by which raising the free intracellular $\mathrm{Ca}^{2+}$ concentration stimulates uterine PG synthesis and release. Presumably $\mathrm{Ca}^{2+}$ combines with calmodulin, which in turn combines with PLA-2 and thereby activates the enzyme to release arachidonic acid for PG synthesis from phospholipids. The main phospholipids involved appear to be phosphatidylcholine and phosphatidylethanolamine (Leaver \& Poyser, 1981; Ning \& Poyser, 1984).

Trifluoperazine has also been shown to inhibit arachidonic acid and/or PG and TX release induced by thrombin in human platelets (Walenga, Opas \& Feinstein, 1981), by A23187, vasopressin, $\mathrm{NaCl}$ and mannitol in rat kidney medulla (Craven \& DeRubertis, 1981 ; Craven, Studer \& DeRubertis, 1981), and by bradykinin in bovine pulmonary artery endothelial cells (Crutchley, Ryan, 


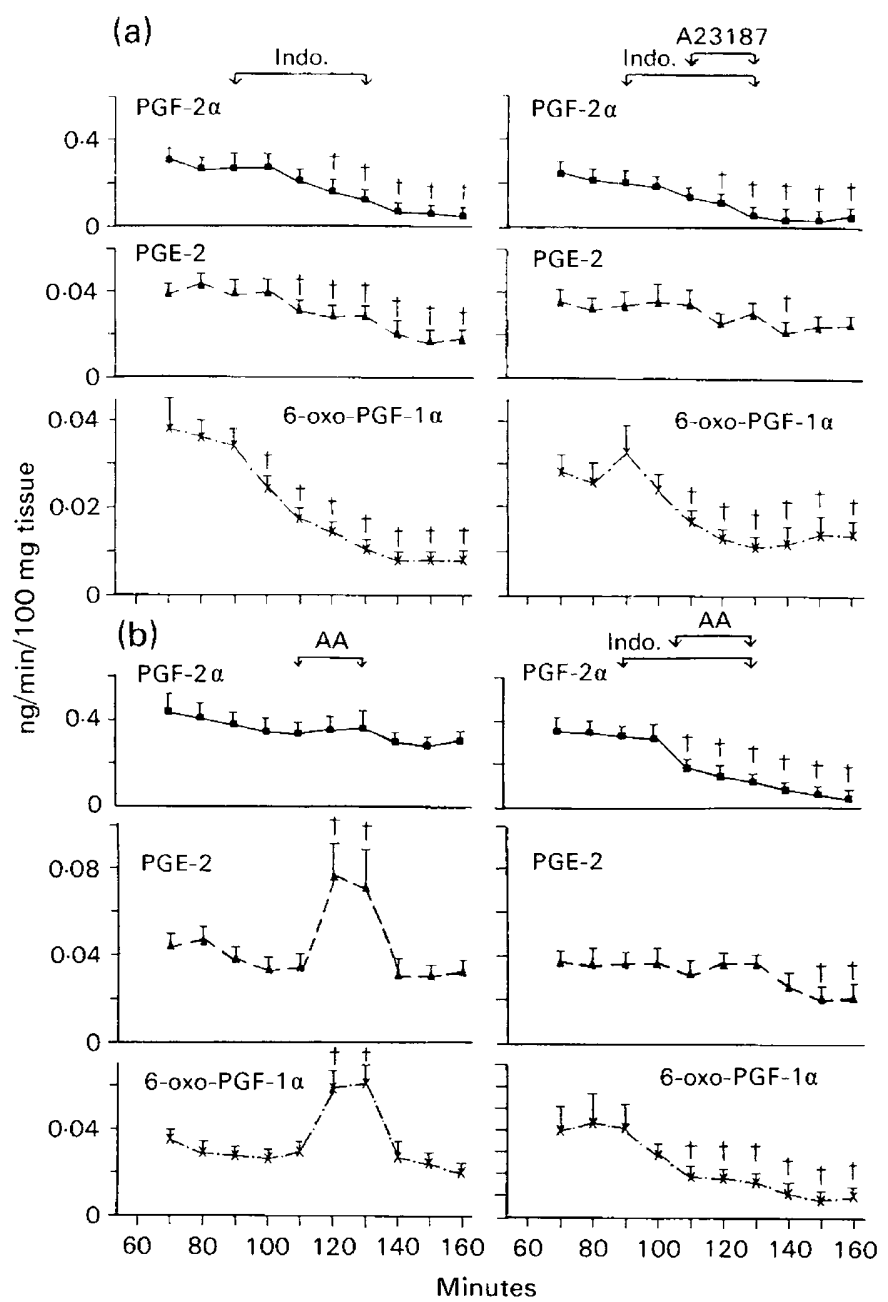

Text-fig. 5. Effect of indomethacin (Indo.; 5.6 $\mu \mathrm{M}$ ) on (a) basal and A23187-stimulated and (b) arachidonic acid-stimulated mean ( \pm s.e.m., $n=5$ ) outputs of prostaglandin (PG) F- $2 \alpha, \mathrm{PGE}-$ 2 and 6-oxo-PGF-1 $\alpha$ from the Day-15 guinea-pig uterus superfused in vitro. For any one PG receiving any particular treatment on only the left-hand or right-hand side: $†$ Significantly different from baseline values $(P<0 \cdot 05)$.

Ryan \& Fisher, 1983). The A23187-induced increase in production of PGI-2 by porcine aortic endothelial cells is inhibited by another calmodulin antagonist, W-7 (Seid, MacNeil \& Tomlinson, 1983). Consequently, $\mathrm{Ca}^{2+}$ activation of PLA-2 via calmodulin appears to have a critical role in controlling PG synthesis in the tissues studied so far.

It is considered that the binding of $\mathrm{Ca}^{2+}$ to calmodulin creates a "hydrophobic domain" on the surface of calmodulin, which is essential for the binding of the $\mathrm{Ca}^{2+}$-calmodulin complex to its acceptor protein. This "hydrophobic domain" is assumed to be the site of trifluoperazine binding (Andersson, Drakenberg, Thulin \& Forsen, 1983). It is also considered that calmodulin is difficult to antagonize if it is already tightly bound to its acceptor protein (Spedding, 1983). This may therefore explain why trifluoperazine had no inhibitory effect on the high basal output of PGF- $2 \alpha$ from the Day-15 uterus, in which PLA-2, the acceptor protein, has probably been activated by $\mathrm{Ca}^{2+}$ calmodulin in vivo before removal. In fact, trifluoperazine caused a small, sometimes significant, in- 
crease in uterine PG output on both Days 7 and 15. Trifluoperazine has been shown to stimulate arachidonic acid release from phosphatidylcholine and phosphatidylethanolamine in guinea-pig macrophages (Takenawa, Homma \& Nagai, 1982), and presumably the liberated arachidonic acid is available for PG synthesis. A similar action of trifluoperazine on the uterus could account for the small stimulation of $P G$ synthesis.

The mechanism by which trifluoperazine releases arachidonic acid from phospholipids is not clear. Chlorpromazine is known to release membrane-bound, intracellular $\mathrm{Ca}^{2+}$ (see Seeman, 1972) and trifluoperazine (a related compound) may have a similar action. The $\mathrm{Ca}^{2+}$ liberated may then combine with calmodulin and activate $\mathrm{PLA}_{2}$ to release arachidonic acid from phospholipids for PG synthesis before the inhibitory effect of trifluoperazine on this process occurs. It might be expected, therefore, that self-inhibition of the stimulatory action of trifluoperazine would take place. However, increased uterine PG output is maintained throughout the period of trifluoperazine superfusion, and uterine PG output falls only after trifluoperazine treatment has ceased (see Text-fig. 1a). Consequently, another mechanism by which trifluoperazine stimulates arachidonic acid from phospholipids may need to be invoked.

Trifluoperazine $(100 \mu \mathrm{M})$ inhibited the A23187-induced contraction of the guinea-pig uterus. This is consistent with calmodulin being involved in contraction of smooth muscle, with $\mathrm{Ca}^{2+}-\mathrm{cal}^{-}$ modulin causing activation of myosin light-chain kinase (see Stevens, 1983). Surprisingly, trifluoperazine did not prevent spontaneous contractions of the uterus, especially as spontaneous contractions do not occur in the absence of extracellular $\mathrm{Ca}^{2+}$ (Poyser, 1984a). Either the spontaneous contractions are not calmodulin-dependent, or trifluoperazine was not blocking calmodulin completely. Arachidonic acid $(1 \mu \mathrm{g} / \mathrm{ml})$ did not cause the uterus to contract, and indomethacin $(5.6 \mu \mathrm{M})$ had no effect on spontaneous or A23187-induced contractions. Endogenous PGs do not therefore appear to be involved in the generation of spontaneous or A23187-induced contraction of the guinea-pig uterus.

Exogenous arachidonic acid increased PGF-2 $\alpha$ output from the Day- 7 but not from the Day-15 guinea-pig uterus although endogenous arachidonic acid (released by the action of A23187) increased PGF- $2 \alpha$ output on Days 7 and 15. This suggests that exogenous arachidonic acid does not reach the site of PGF- $2 \alpha$ production on Day 15. This may be due to the greater rate of uptake of arachidonic acid into endometrial phospholipids on Day 15 compared to Day 7 (Ning, Leaver \& Poyser, 1983), especially as the endometrium is the major site of PGF-2 $\alpha$ synthesis (Poyser, 1983b). However, exogenous arachidonic acid increased 6-oxo-PGF-1 $\alpha$ and PGE-2 outputs on Day 15, suggesting that PGF- $2 \alpha$ synthesis and the increase in arachidonic acid uptake occurs in a cell type different from that involved with 6-oxo-PGF-1 $\alpha$ and PGE-2 synthesis. The myometrium is the major site of 6-oxo-PGF-1 $\alpha$ production (Poyser, 1983b). Furthermore, exogenous arachidonic acid caused a much greater stimulation of PGE-2 output than did endogenous arachidonic acid released by the action of $\mathrm{A} 23187$. This suggests that endogenous arachidonic acid is not readily available to the PGE-2-forming sites within the cell, and/or cells that can synthesize PGE-2 are not readily activated to do so by $\mathrm{A} 23187$.

Overall, these studies provide evidence that calmodulin is involved in the biochemical processes that lead to an increase in PG secretion from the guinea-pig uterus in response to raising the intracellular free $\mathrm{Ca}^{2+}$ concentration. However, further studies are required to see whether the increase in PGF- $2 \alpha$ output from the guinea-pig uterus after Day 11 of the cycle, probably in response to oestradiol acting on a progesterone-primed uterus (Blatchley \& Poyser, 1974; Poyser, 1983a), involves calmodulin. Nevertheless, it has been shown that oestradiol on the rat uterus (Flandroy, Cheung \& Steiner, 1983), and oestradiol or progesterone on the rabbit myometrium (Matsui et al., 1983), increase the concentration of calmodulin, indicating that calmodulin synthesis in the uterus is under ovarian hormonal control.

The technical help of Miss Isa Ramsay is greatly appreciated. Authentic PGs were kindly supplied by the Upjohn Co., Kalamazoo, Michigan, U.S.A. 


\section{References}

Andersson, A., Drakenberg, T., Thulin, E. \& Forsen, S. (1983) Interaction of calmodulin with D600, trifluoperazine and some other lipophilic drugs. Eur. $J$. Biochem. 134, 459-465.

Blatchley, F.R. \& Poyser, N.L. (1974) The effect of oestrogen and progesterone on the release of prostaglandins from the uterus of the ovariectomized guinea-pig. J. Reprod. Fert. 40, 205-209.

Craven, P.A. \& DeRubertis, F.R. (1981) Effects of vasopressin and urea on $\mathrm{Ca}^{2+}$-calmodulin-dependent renal prostaglandin E. Am. J. Physiol. 241, F649F658.

Craven, P.A., Studer, R.K. \& DeRubertis, F.R. (1981) Renal inner medullary prostaglandin synthesis. $J$. clin. Invest. 68, 722-732.

Crutchley, D.J., Ryan, J.W., Ryan, U.S. \& Fisher, G.H. (1983) Bradykinin-induced release of prostacyclin and thromboxanes from bovine pulmonary artery endothelial cells. Studies with lower homologs and calcium antagonists. Biochim. Biophys. Acta 751, 99107.

Downing, I. \& Poyser, N.L. (1983) Estimation of phospholipase $\mathrm{A}_{2}$ activity in guinea-pig endometrium on Days 7 and 16 of the estrous cycle. Prostaglandins, Leuk. \& Med. 12, 107-117.

Flandroy, L., Cheung, W.Y. \& Steiner, A.L. (1983) Immunofluorescent localization of cGMP, cGMPdependent protein kinase, calmodulin and cAMP in the rat uterus. Effects of estrogen treatment. Cell Tissue Res. 233, 639-646.

Leaver, H.A. \& Poyser, N.L. (1981) Distribution of arachidonic acid and other fatty acids in the lipids of guinea-pig uterus and plasma in relation to uterine prostaglandin synthesis. J. Reprod. Fert. 61, 323335.

Levin, R.M. \& Weiss, B. (1977) Binding of trifluoperazine to the calcium dependent activator of cyclic nucleotide phosphodiesterase. Molec. Pharmac. 13, 690-697.

Maskowitz, N.L., Shapiro, L., Schook, W. \& Puzkin, S. (1983) Phospholipase $A_{2}$ modulation by calmodulin, prostaglandins and cyclic nucleotides. Biochem. Biophys. Commun. 115, 94-99.

Matsui, K., Higashi, K., Fukunaga, K., Miyazaki, K., Maeyama, M. \& Miyamoto, E. (1983) Hormone treatments and pregnancy alter myosin light chain kinase and calmodulin levels in rabbit myometrium. $J$. Endocr. 97, 11-20.

Mitchell, S., Poyser, N.L. \& Wilson, N.H. (1977) Effect of p-bromophenacyl bromide, an inhibitor of phospholipase $A_{2}$, on arachidonic acid release and prostaglandin synthesis by the guinea-pig uterus. $B r$. J. Pharmac. 59, 107-113.

Ning, A.C.W.S. \& Poyser, N.L. (1984) Further studies on the control of arachidonic acid turnover in guinea-pig endometrium in relation to prostaglandin production. Prostaglandins, Leuk. \& Med. (in press).
Ning, A.C.W.S., Leaver, H.A. \& Poyser, N.L. (1983) Arachidonic acid uptake into and release from guinea-pig endometrium in vitro on Days 7 and 15 of the oestrous cycle. Prostaglandins, Leuk. \& Med. 10, 369-380.

Poyser, N.L. (1976) Prostaglandin is the uterine luteolytic hormone in the guinea-pig: the evidence reviewed. Adv. Prostaglandin Thromboxane Res. 2 , 633-643.

Poyser, N.L. (1981) Prostaglandins in Reproduction. John Wiley \& Sons Ltd, Chichester.

Poyser, N.L. (1983a) Effect of treating ovariectomized guinea-pigs with estradiol and progesterone on basal and A23187-stimulated release of prostaglandins from the uterus superfused in vitro. Prostaglandins, Leuk. \& Med. 11, 345-360.

Poyser, N.L. (1983b) Differential stimulation of prostaglandin and thromboxane synthesizing capacities in guinea-pig uterus and ovary, Prostaglandins, Leuk. \& Med. 10, 163-177.

Poyser, N.L. (1984a) Effect of using calcium-free Krebs' solution on basal and A23187-stimulated prostaglandin output from the Day 15 guinea-pig uterus superfused in vitro. Prostaglandins, Leuk. \& Med. 13, 259-269.

Poyser, N.L. (1984b) Prostaglandin production by the early pregnant guinea-pig uterus in relation to implantation and luteal maintenance, and the effect of oestradiol. J. Reprod. Fert. 72, 117-127.

Poyser, N.L. \& Brydon, L.J. (1983) Prostaglandin release from the guinea-pig uterus superfused in vitro. Effect of stage of estrous cycle, progesterone, estradiol, oxytocin and A23187. Prostaglandins 25, 443-456.

Seeman, P. (1972) Erythrocyte membrane stabilisation by tranquilisers and antihistamines. Pharmac. Rev. 24, 583-655.

Seid, J.M., MacNeil, S. \& Tomlinson, S. (1983) Calcium, calmodulin, and the production of prostacyclin by cultured vascular endothelial cells. Biosci. Rep. 3, 1007-1015.

Spedding, M. (1983) Direct inhibitory effects of some "calcium antagonists" and trifluoperazine on the contractile proteins in smooth muscle. Br. J. Pharmac. 79, 225-232.

Stevens, F.C. (1983) Calmodulin : an introduction. Can. J. Biochem. Cell Biol. 61, 906-910.

Takenawa, T., Homma, K. \& Nagai, Y. (1982) Effect of calmodulin antagonists on lysosomal enzyme secretion and phospholipid metabolism in guinea-pig macrophages. Biochem. J. 208, 549-558.

Walenga, R.W., Opas, E.E. \& Feinstein, M.B. (1981) Differential effects of calmodulin antagonists on phospholipase $\mathrm{A}_{2}$ and $\mathrm{C}$ in thrombin-stimulated platelets. J. biol. Chem. 256, 12523-12528.

Wong, P.Y.K. \& Cheung, W.Y. (1979) Calmodulin stimulates human platelet phospholipase $\mathbf{A}_{2}$. Biochem. Biophys. Res. Commun. 90, 473-480. 